\title{
The onset area of Ice Stream D, West Antarctica
}

\author{
Robert Bindsahadler, ${ }^{1}$ Xin Ghen, ${ }^{2}$ Patriaia Vornberger ${ }^{2}$ \\ ${ }^{1}$ NASA Goddard Space Flight Center, Code 971, Greenbelt, Maryland 20771, U.S.A. \\ ${ }^{2}$ General Sciences Corporation, Laurel, Maryland 20727, U.S.A.
}

\begin{abstract}
Surface flow in a $10000 \mathrm{~km}^{2}$ expanse of the onset area of Ice Stream D, West Antarctica, was measured by repeat, precise global positioning system surveys over a 1 year interval. The pattern of velocity and strain rate shows the development of Ice Stream D, the major flow into which originates south of Byrd station and follows the course of a deep bed channel. Plotting of the driving stress vs the ratio of velocity and ice thickness identifies the onset of streaming flow (roughly $140 \mathrm{~km}$ downstream of Byrd station) as a transition between deformation flow and sliding flow. Along the kinematic center line of the developing ice stream, the ice rheology is linear at stresses below 0.6 bar, and appears temperate at the base well before the onset of streaming is reached. The onset corresponds to a maximum driving stress of 0.8 bar. It occurs downstream of a slight increase in longitudinal strain rate where stronger along-flow lineations are apparent in Landsat imagery, and after the ice has passed the center of an overdeepening in the bed channel. No current deviation from equilibrium is detected in this region, but a set of flow stripes misaligned with present flow indicates significant changes in flow have occurred in the past.
\end{abstract}

\section{INTRODUCTION}

Ice streams are critical dynamic elements of the West Antarctic ice sheet, yet little is known about the process responsible for their initiation. Their relatively rapid speeds (a few hundred meters per year), considerable widths (typically $50 \mathrm{~km}$ ) and kilometer depths make them the dominant discharge conduits from the ice sheet. High speed and great depth also result in a short response time-scale, providing an avenue for rapid transmission inland of dynamic effects nearer the coast (Bindschadler, 1997).

Numerous studies have addressed the mechanical processes that govern the speed of ice streams at their bases, across their margins and at their mouths (where they enter the ice shelf) (MacAyeal and others, 1987; Alley, 1990; Kamb, 1991; Raymond, 1996; Anandakrishnan and Alley, 1997b; Engelhardt and Kamb, 1997; Whillans and Van der Veen, 1997; Jacobson and Raymond, 1998). However, few studies have examined the transition from slow, inland icesheet flow to rapid ice-stream flow (Hughes, 1977; McIntyre, 1985; Whillans, 1987; Alley, 1990). Ice streams move rapidly by sliding at or within their basal till (Engelhardt and Kamb, 1997). Sustaining high sliding rates, by lubricating meltwater created from subglacial frictional heating, is less puzzling than how the fast flow is initiated.

The term "onset" commonly refers to the region where ice flow changes from a combination of internal deformation and basal sliding characteristic of most of an ice sheet, to a streaming mode of flow where a well-lubricated bed enables high speeds at low driving stresses (Bentley, 1987). The spatial scale over which this transition in ice dynamics takes place remains unknown. Until the processes responsible for ice-stream initiation are understood, the future of the ice sheet cannot be predicted.

Proxy onset indicators (discussed below) have been suggested but not verified. Our approach is aimed at identify- ing the regions where the dynamic relationship between driving stress and speed fits an internal-deformation/basalsliding mode and where it fits a streaming mode. In so doing, we find that a localized transition region can be identified, and proxy onset indicators can be evaluated.

\section{PREVIOUS ONSET-LOGATION TEGHNIQUES}

Optical satellite imagery has been used to discriminate between the more undulating surfaces of ice streams at the many-kilometer scale and the smoother, slower inter-stream ridges (Bindschadler and Vornberger, 1990; Scambos and Bindschadler, 1991). The inland regions are also undulating, requiring higher-resolution imagery to identify longitudinal flow stripes many tens of meters across which can form when the ratio of sliding velocity to internal deformation is high (Gudmundsson and others, 1998). Such sites are frequently observed in high-resolution imagery and are usually associated with, but not always connected to, an ice stream (Stephenson and Bindschadler, 1990; Scambos and Bindschadler, 1991; Hodge and Doppelhammer, 1996). The most upstream transverse crevasse might also serve as an indication of onset, insofar as transverse crevasses are formed by longitudinal tension, but it is not known if tensile stresses sufficient to form transverse crevasses occur at all onsets. Similarly, marginal crevasses indicate intense shear, but if the velocity difference between an ice stream and adjacent ice is distributed over a longer distance, shear stress is reduced and marginal crevasses may not form. In short, precise location of the onset cannot be based on imagery alone.

Hughes (1977) characterized the onset as occurring where the longitudinal elevation profile displayed an inflection point. He argued that for inland flow the elevation profile is described by the classic, convex-up, near-parabolic shape, while for an ice stream the longitudinal surface 
profile must be concave-up, with slope decreasing alongflow and eventually merging with the very shallow-sloped ice shelf. Thus, the transition in flow should coincide with the inflection point of this elevation profile where driving stress was highest. In practice, however, the surface is rough on the scale of many kilometers, and the smoothing required to discern the inflection point makes precise location of the onset difficult.

Attempts have been made to correlate onsets with bed channels. McIntyre (1985) found that the sheet-flow to stream-flow transition of Antarctic outlet glaciers is correlated with steps in the bedrock, but that this correlation does not, in general, hold inWest Antarctica. Bell and others (1996) located one site in West Antarctica where they feel this correlation holds.

The major limitation to all of these techniques is the absence of velocity data. Because the onset is defined as a transition in the mode of ice flow, from internal deformation to basal sliding, confirmation of its location requires velocity data.

\section{DATA}

Data from previous field research were combined with satellite data to plan the collection of surface observations. Surface motion at New Byrd station was reported as $13 \mathrm{ma}^{-1}$, based on a surface survey that extended to the ice divide where zero velocity was assumed (Whillans, 1979). Approximately $160 \mathrm{~km}$ downstream of Byrd station, a speed of $130 \mathrm{~m} \mathrm{a}^{-1}$ was determined by sequential Landsat imagery for the most inland crevasses on Ice Stream D (Bindschadler, and others, 1996). This order-of-magnitude increase in speed, along with the development of flow stripes visible in the imagery, strongly suggested the onset of streaming flow occurred somewhere between Byrd station and the crevasses.

Other lineations in the Landsat imagery suggested converging flow into the region where the existence of streaming flow was likely (Fig. 1). Co-registration of the bedelevation field with the satellite imagery showed the strongest lineations followed the course of an overdeepened bed channel (Bamber and Bindschadler, 1997). The channel floor dips to $>1000 \mathrm{~m}$ below sea level, while on either side of the channel the bed rises $500 \mathrm{~m}$ above the channel bottom. The bedrock ridge to the north lies just downstream of Byrd station. Figure 1 includes the flight-lines to illustrate that most of the major bed features are sampled, albeit sparsely. Surface elevation decreases by $400 \mathrm{~m}$ over this region, from roughly $1500 \mathrm{~m}$ at Byrd station to roughly $1100 \mathrm{~m}$ at the crevasse field. Ice thickness averages approximately $2000 \mathrm{~m}$ but varies by up to $\pm 500 \mathrm{~m}$ from this value.

Based on this preliminary work, a surface grid was planned extending from Byrd station to just upstream of the crevasse field, spanning the expected converging flow field. A regular $5 \mathrm{~km}$ spacing of stakes was used (2.5 times the average ice thickness), resulting in 319 stakes. Fifty-two additional stakes were distributed among 11 selected sites where interesting imagery features suggested a more detailed survey might be fruitful. Finally, 13 other stakes were relocated over the downstream part of the Byrd Station Strain Network (BSSN) surveyed in 1963/64 and 1967/ 68 to investigate the possible temporal change in the strain field (Whillans, 1979).

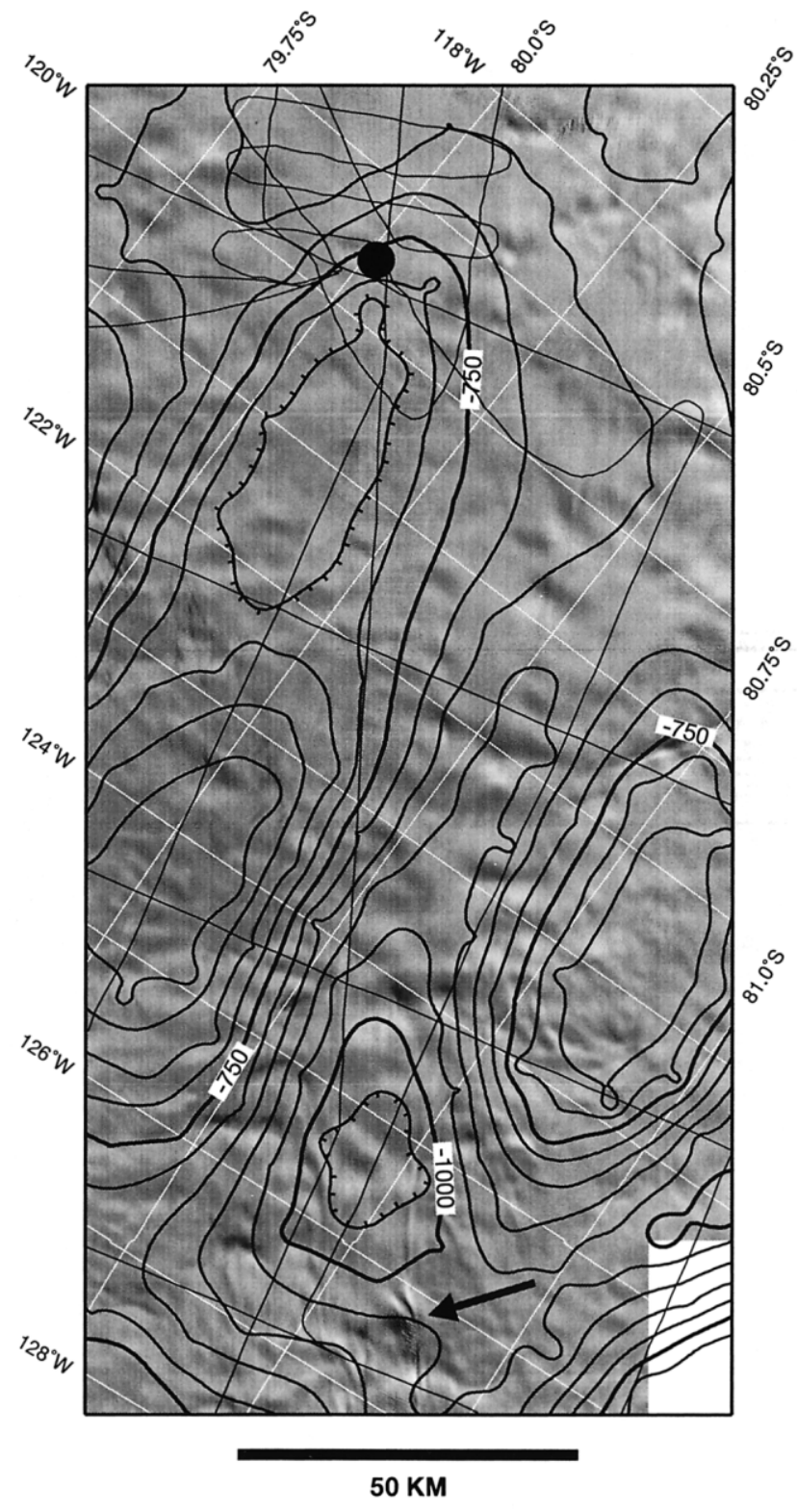

Fig. 1. Composite of Landsat imagery, bed-elevation contours and flight-lines along which bed-elevation data were collected. Ice thicknesses were measured by airborne radar soundings (Drewry, 1983), converted to bed elevations with a mean sea-level datum, and interpolated to a $10 \mathrm{~km}$ grid (Bamber and Bindschadler, 1997). Flight-lines are thin lines with a quasi-regular spacing of $50 \mathrm{~km}$. Contour interval of bed elevations is $50 \mathrm{~m}$. Location of Byrd station is indicated by solid circle. Arrow points to most upstream crevasse field.

The grid was established during November-December 1995 by a five-person survey team using snowmobiles to visit each site and using Ashtech Z-12 global positioning system (GPS) receivers to determine stake positions. The grid was resurveyed the following year in an identical manner. Details of the survey methods used and processing of the data are reported in Chen and others $(1996,1998)$. They report average position precisions of $8 \mathrm{~cm}$ in the horizontal and $14 \mathrm{~cm}$ in the vertical.

\section{SURFACE VELOGITY}

The primary result from the survey is the surface velocity field (Fig. 2). The values range from $10 \mathrm{~m} \mathrm{a}^{-1}$ near Byrd station to $>100 \mathrm{~m} \mathrm{a}^{-1}$ at the grid's downstream end, in close ac- 


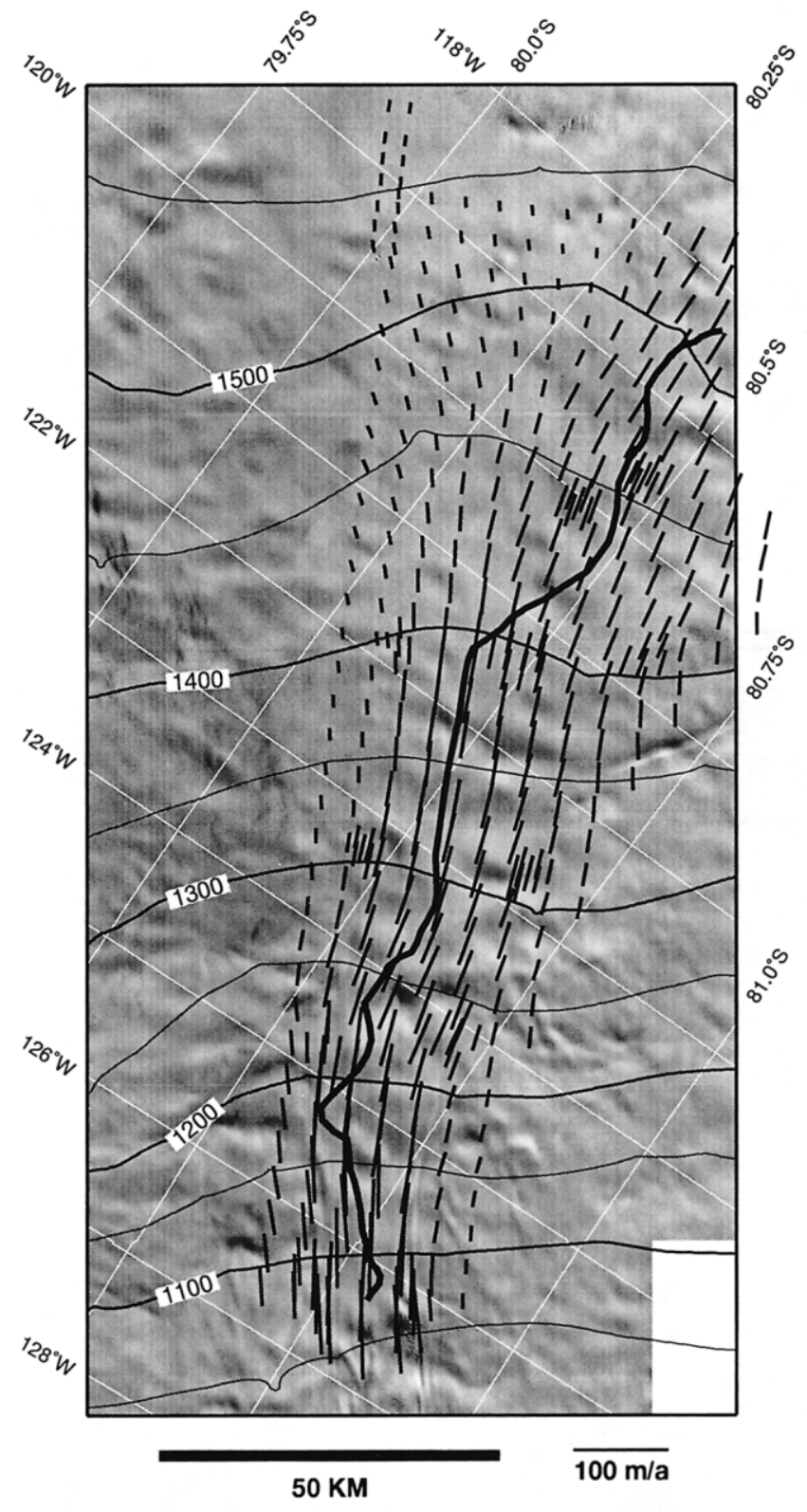

Fig. 2. Measured velocities superimposed on Landsat imagery and surface elevation contours. Elevation measurements are from satellite radar altimetry (Bamber, 1994) and are referenced to mean sea level. Heavy line indicates the kinematic center line discussed in text.

cord with the preliminary estimate. From the average precision of horizontal positions, speeds have a $1 \sigma$ accuracy of $0.1 \mathrm{~m} \mathrm{a}^{-1}$. Directional accuracy depends on speed.

The primary flow enters the grid from the southeast and turns gradually westward before exiting at the downstream end. The flow field confirmed most of the imagery-based interpretations of flow direction, and generally conforms with the flow direction expected from the elevation contours. Deviations from the predicted and measured flow directions are slight and depend on the specific choice of averaging length applied to the elevation field. The direction of flow also conforms to the presence and orientation of the bed channel.

The speed at Byrd surface camp was measured to be $11.6 \pm 0.1 \mathrm{~m} \mathrm{a}^{-1}$, less than the previous measurement at New Byrd station and directed $10^{\circ}$ farther clockwise. Byrd surface camp is located approximately $2 \mathrm{~km}$ northwest of the original New Byrd station location and can be seen in Figure 2 as a small hill near the end of the leftmost line of BSSN velocity vectors. Due to the assumptions used with the earlier New Byrd station velocity estimate and the similarity of the BSSN strain rates over the 30 year interval (discussed below), we attribute no significance to this velocity difference related to possible changes in ice flow. Although the ice thickness is relatively constant across the upstream end of the grid, and the surface slopes slightly higher near Byrd station than to the south, the speeds are slower near Byrd station than to the south. This may be due to the large basal ridge obstructing the flow downstream (see Fig. 1). Other possibilities are that the downstream effect of an even larger, previously undetected, subglacial massif reported southeast (i.e. upstream) of Byrd station (personal communication from D. D. Blankenship, 1996) steers ice flow to the south so it enters the grid from the southeastern corner, or that the velocity is affected by differences in material properties of the ice or underlying till (discussed below).

Because flow direction is not precisely parallel to the long axis of the grid, a kinematic center line is identified by the maximum velocity at a series of across-flow transects (see Fig. 2). Lateral shear is at a minimum along this kinematic center line which begins about $15 \mathrm{~km}$ from the grid's southeastern corner and roughly follows the axis of the bed channel. Figure 3 shows profiles of surface and bed elevation, ice thickness and surface speed along the kinematic center line. Surface elevation decreases steadily. The overdeepening occurs $140 \mathrm{~km}$ downstream from the upstream origin of the grid (or $20 \mathrm{~km}$ upstream from the grid's downstream limit), after which the thickness decreases downflow. Speed increases monotonically with two changes in velocity gradient: the first at longitudinal grid distance $65 \mathrm{~km}$, nearly coincident with the largest turn in the direction of the center line; and the second at $130 \mathrm{~km}$, also at a kink in the path of the center line, very close to the thickness maximum but $10 \mathrm{~km}$ upstream of the maximum overdeepening. These locations are discussed below after further analysis.

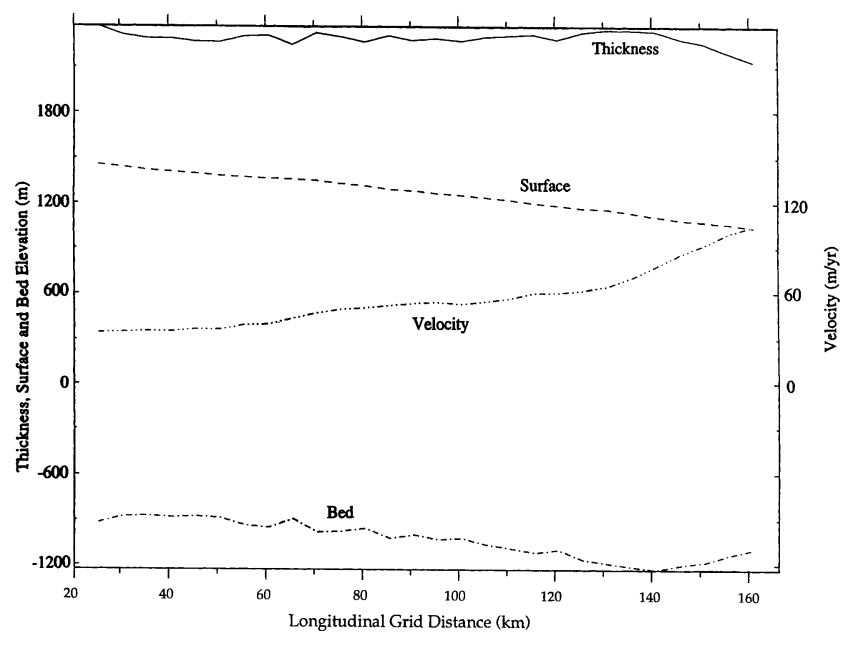

Fig. 3. Profiles of surface and bed elevation, ice thickness and speed along the kinematic center line. Distance is referenced to the upstream end of the survey grid.

\section{STRAIN RATES}

Principal strain rates are calculated from the velocity field and shown in Figure 4. Expected errors are $3 \times 10^{-5} \mathrm{a}^{-1}(1 \sigma)$. The major feature is increasing side shear which develops as 


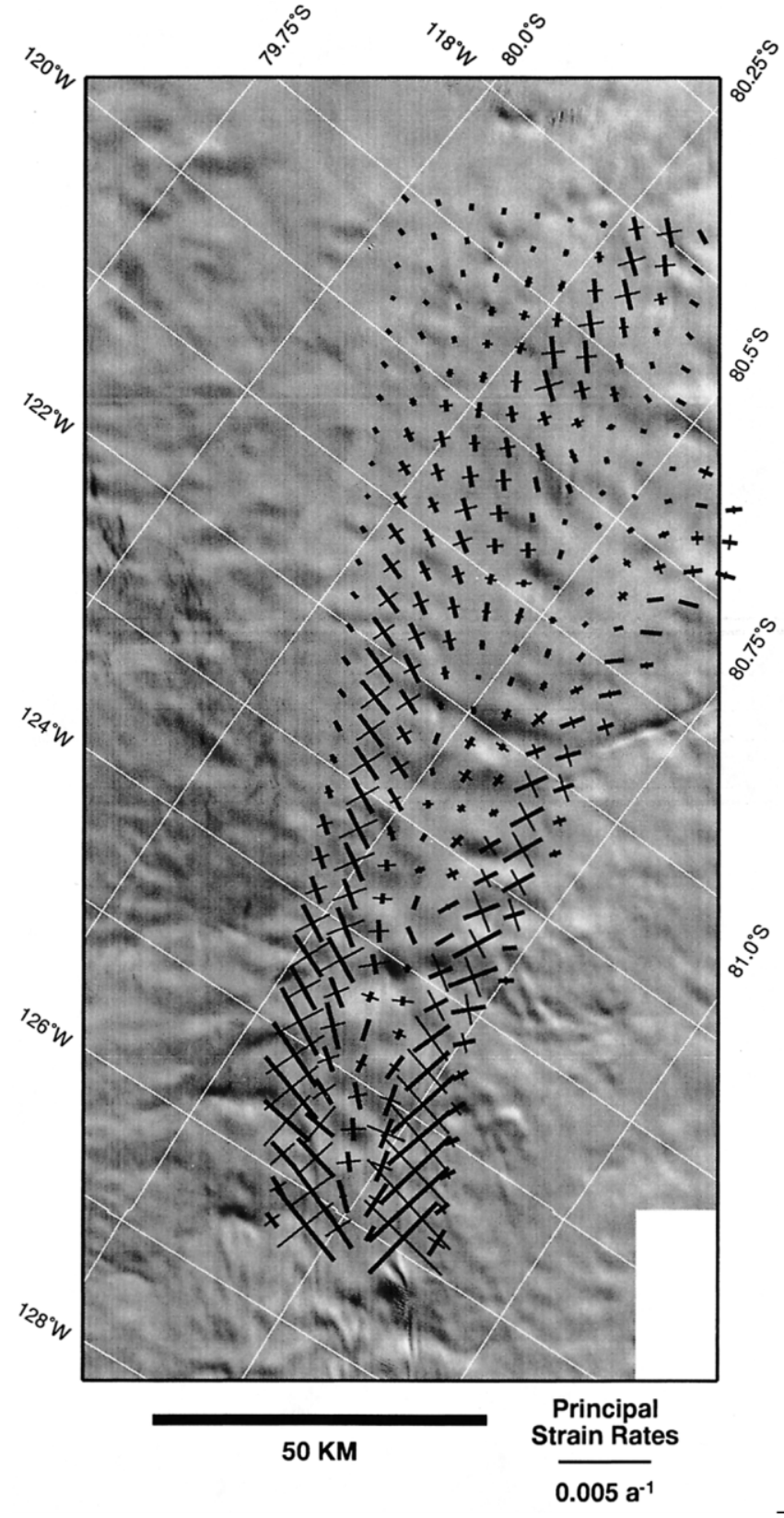

Fig. 4. Principal strain rates calculated from the velocity field. Bold lines are principal tensile component, while thin lines are principal compression.

the ice stream forms. Flow-oriented strain rates (not shown) illustrate the expected pattern in a region of converging and accelerating flow: longitudinal strain rates are nearly all positive, and transverse strain rates are nearly all compressive. An exception to this pattern occurs along the southern edge of the grid where longitudinal strain rates are compressive and transverse strain rates are tensile. Deviations from this pattern are also seen on the scale of the grid spacing (2.5 times the average ice thickness), presumably resulting from local effects induced by the local variations in ice thickness. Vertical strain rates, calculated from the incompressibility condition as minus the sum of the surface-horizontal strain rates, result in a mixture of positive and negative values with little spatial coherence (not shown).

\section{DETERMINATION OF ONSET LOGATION}

The elevation profile (see Fig. 3) shows no apparent inflection point which might suggest the onset location. Trans- verse velocity profiles centered on the kinematic center line and Figure 4 both show the gradual development of increasing shearing downstream as the ice-stream margin develops, but no sudden change in flow character is apparent. The kinks in the longitudinal velocity profile are also inconclusive.

Our method of identifying the onset location uses the laminar-flow approximation to determine the region where ice flow shifts from being dominated by basal shear stress ("sheet flow") to being nearly independent of basal shear stress ("streaming flow"). Laminar flow is a reasonable approximation in the ice-sheet interior, far from the ice divide. The vertically integrated form of the laminar-flow equation for ice deformation is

$$
u_{\mathrm{s}}=u_{\mathrm{b}}+[2 A /(n+1)] \tau_{\mathrm{b}}{ }^{n} H,
$$

where $u_{\mathrm{s}}$ and $u_{\mathrm{b}}$ are the surface and bed velocities, respectively, $A$ and $n$ are the depth-averaged temperature-dependent coefficient and exponent of the non-linear flow law, $H$ is the ice thickness and $\tau_{\mathrm{b}}$ is the basal shear stress (Paterson, 1994). In the absence of other major stresses, the basal shear stress can be approximated by the gravitational driving stress, $\tau_{\mathrm{d}}$, expressed as

$$
\tau_{\mathrm{d}}=\rho g H \sin \alpha
$$

where $\rho, g$ and $\alpha$ are ice density, gravitational acceleration and surface slope, respectively. Surface slopes at each point are calculated by fitting a plane to a centered $40 \mathrm{~km} \times 40 \mathrm{~km}$ area. Large-scale surface slopes minimize the effect of longitudinal stress gradients. If basal sliding is assumed negligible (i.e. $u_{\mathrm{b}}=0$ ), Equation (1) can be rearranged to

$$
\ln \left(u_{\mathrm{s}} / H\right)=C+n \ln \left(\tau_{\mathrm{d}}\right)
$$

where

$$
C=\ln [2 A /(n+1)],
$$

which describes a linear relationship between $\ln \left(u_{\mathrm{s}} / H\right)$ and $\ln \left(\tau_{\mathrm{d}}\right)$. The effect of assuming negligible basal sliding is discussed below.

Calculations were completed for a more dense, $1 \mathrm{~km}$ spaced grid by interpolating velocity data from the survey grid and from published surface elevations and ice thicknesses (Bamber and Bindschadler, 1997). Figure 5 shows the distribution of $\ln \left(\tau_{\mathrm{d}}\right)$ vs $\ln \left(u_{\mathrm{s}} / H\right)$ for all points of the original survey grid. To emphasize the pattern along the centerline, all center-line points of the $1 \mathrm{~km}$ grid are plotted in the figure as open circles.

The center-line profile in Figure 5 exhibits a "stair-step" character. This shape is primarily the result of surface-slope variations. It begins at minimum driving stresses of about 0.4 bar. The profile segments of decreasing driving stress (near $\ln \tau_{\mathrm{d}}=-0.9$ and -0.5 ) correspond to short intervals of shallower surface slopes. The bottom of the most downstream step $\left(\ln \tau_{\mathrm{d}}=-0.3\right)$ corresponds to the more downstream kink in the velocity profile (identified earlier) where longitudinal strain rates increase. The vertical step following this point is the result of driving stress increasing while increasing velocity is offset by increasing ice thickness (entering the overdeepening), so $\ln \left(u_{\mathrm{s}} / H\right)$ changes little. Once the overdeepening's center is passed, ice thickness decreases while velocity increases, causing $\ln \left(u_{\mathrm{s}} / H\right)$ to increase again.

Driving stress reaches a maximum value of 0.8 bar $10 \mathrm{~km}$ upstream from the end of the center line. Other flowlines 


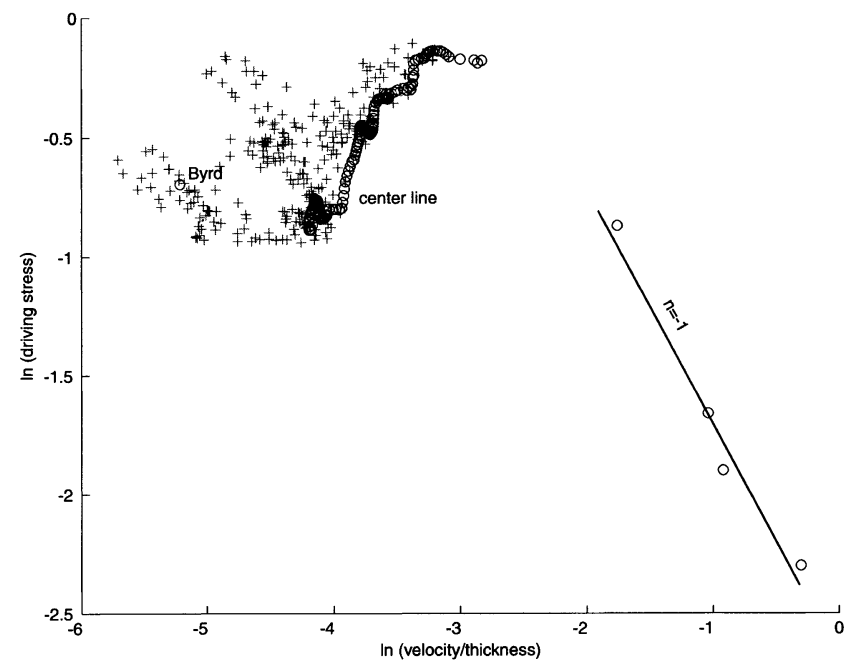

Fig. 5. Plot of $\ln \left(\tau_{\mathrm{d}}\right)$ vs $\ln \left(u_{\mathrm{s}} / H\right)$ for points in the survey grid. Open circles lie on the kinematic center line. Lines indicate different ice rheologies using flow-law parameters discussed in text. $\theta$ is temperature. Arrow indicates onset where type of flow changes.

parallel to the center line describe similar traces, all with a similar maximum driving stress. Downstream of this point, driving stress decreases while $u_{\mathrm{s}} / H$ increases. This trend for driving stress to decrease downstream while velocity increases and thickness decreases is characteristic of ice streams (Whillans and Van der Veen, 1993). Using values of driving stress from Drewry (1983) and of velocity and thickness from Bindschadler and others (1996) for five points along the main ice-stream trunk, Figure 6 shows that Ice Stream D follows this pattern. These trunk points are fit with a line of slope $n=-1$ and appear consistent with the downstream end of the center line. Because the maximum driving stress identifies the boundary between an upstream flow regime consistent with laminar flow and a downstream flow regime consistent with streaming flow, this point represents the onset of Ice Stream D. Using this method, the onset location can be identified to the resolution of the grid.

The onset occurs $10 \mathrm{~km}$ upstream of the grid's downstream end. It lies downstream of the kinks in the velocity profile and the center of the overdeepening (Fig. 3); how-

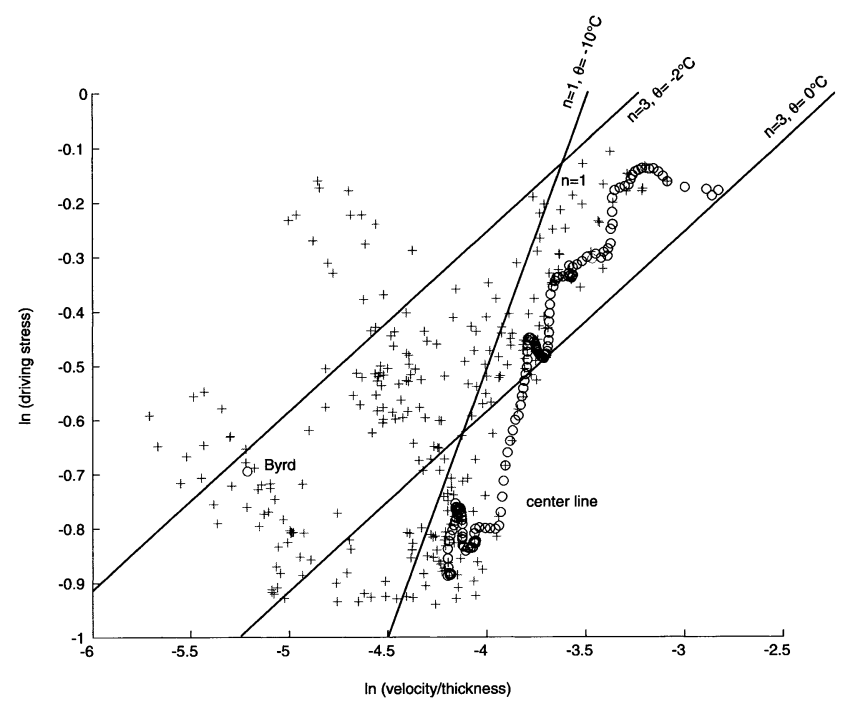

Fig. 6. Plot of $\ln \left(\tau_{\mathrm{d}}\right)$ vs $\ln \left(u_{\mathrm{s}} / H\right)$ for survey gridpoints, kinematic center line and four additional positions on the trunk of Ice Stream D. Line corresponds to a flow-law exponent of -1 . ever, given the coarseness of the radar-sounding flight-lines, the position of the overdeepening's center is not precisely known (Fig. 1). Refinement of the basal topography will be possible once a $5 \mathrm{~km}$ spaced set of airborne radio-echo sounding data is examined (personal communication from D. D. Blankenship, 1996). The onset position defined above also occurs downstream of the upstream limit of the more noticeable flow stripes in the imagery. A recent theory of flow-stripe formation requiring sliding to be far more significant than the internal deformation contribution to ice motion suggests that sliding is significant upstream of the onset (Gudmundsson and others, 1998).

\section{ICE RHEOLOGY}

Three different ice rheologies are included in Figure 5 using published flow parameters (Paterson, 1980, 1994). The two non-linear rheologies $(n=3)$ correspond to ice at $0^{\circ}$ and $-2^{\circ} \mathrm{C}$, while the linear rheology corresponds to a temperature of $-10^{\circ} \mathrm{C}$. The temperatures represent effective column temperatures, more indicative of temperatures in the deeper ice where most deformation occurs.

Each rheological condition in Figure 5 assumes no basal sliding, yet there is evidence basal temperatures are at the pressure-melting point at Byrd (Whillans, 1983) and possibly elsewhere within the grid area (Rose, 1979). Any sliding contribution would reduce the correct velocity to be used in Equation (3) and shift the data in Figure 5 to the left. The scatter of data in Figure 5 probably represents spatially variable sliding. Data along the kinematic center line lie farthest to the right, suggesting that these data include the largest amount of sliding. The cluster of data near the Byrd data point all occur in the corner of the grid near Byrd station. Thus, we infer that basal sliding is most prevalent in the center of the bed channel as the ice stream develops.

Paterson (1980) states that several workers claim $n=1$ is appropriate for stresses below 0.5 bar. The slope of the center-line points in Figure 5 is roughly in agreement with $n=1$ for driving stresses of 0.7 bar. This observation supports the linear behavior which has been noticed in other low-stress regimes (Budd, 1969; Doake and Wolff, 1985). T. J. Hughes (personal communication, 1997) has suggested that the $n=1$ region may be the result of relatively higher stresses other than the basal shear stress, but our measurements show that horizontal strain rates are small and that basal shear stress is never a minor component over most of the grid.

At higher stresses, the slope of the center-line profile in Figure 5 increases, eventually approaching $n=3$. The fact that these data fall within the temperature range $0^{\circ}$ to $-2^{\circ} \mathrm{C}$ for a flow-law exponent of $n=3$ only means that these speeds are comparable to those expected of near-temperate ice at these driving stresses. The likelihood of sliding, the possibility that both fabric-enhanced flow and depth-varying flow parameters exist, makes it more probable that the ice in the downstream part of the survey grid is colder through most of the column and sliding at its base.

\section{INDIGATIONS OF EQUILIBRIUM AND NON- EQUILIBRIUM CONDITIONS}

A number of brief analyses are presented below on the issue of whether the onset region is in equilibrium. The first deals with mass continuity, the second with the flow direction ex- 
pected from the elevation field, the third with strain-rate measurements repeated after 30 years, and the fourth with flow stripes compared with the measured flow field.

\section{Mass continuity}

Mass continuity permits the calculation of rates of thickness change from geometry and flow measurements. For any given gridcell, the rate of thickness change within the corresponding three-dimensional column is

$$
\partial H / \partial t=A-(\operatorname{div} \mathbf{Q}) / \delta
$$

where $A$ is the accumulation rate, $\delta$ is the grid spacing, $\mathbf{Q}$ is the volume flux across the vertical face of a column of width $\delta$, and div is the horizontal divergence. Accumulation values were taken from stake measurements (1 year average), firn cores collected at Byrd station (30 year average) and published maps (Bentley and Giovinetto, 1991). The spatial gradient of accumulation from our annual measurements matched closely with published maps, and the firn measurement matched the mapped values, so mapped values were used in the application of Equation (5).

No distinctive pattern of thickness change resulted from applying Equation (5), so the results are not shown here. The uncertainty of the method estimated $1 \sigma$ is approximately $0.3 \mathrm{~m} \mathrm{a}^{-1}$.

\section{Flow direction}

Flow direction was compared with the larger-scale surface topography. Three elevation datasets were analyzed: GPSsurveyed elevations at a $5 \mathrm{~km}$ spacing; an elevation dataset at a $10 \mathrm{~km}$ spacing derived primarily from satellite radar altimetry (Bamber, 1994); and a dataset at $2 \mathrm{~km}$ resolution, also derived from satellite radar altimetry, but using a different algorithm (unpublished information from M. Stenoien and C. R. Bentley). Although differences in specific elevations were observed, gridded surface slopes were quite similar. Averaging lengths of 20 and $40 \mathrm{~km}$ were used (roughly 10 and 20 times the ice thickness). In general, the longer averaging length gave better agreement with the flow direction.

Basal hydropotentials were also calculated from the surface- and bed-elevation data. These potential surfaces define the hydraulic gradient which determines the flow dir-

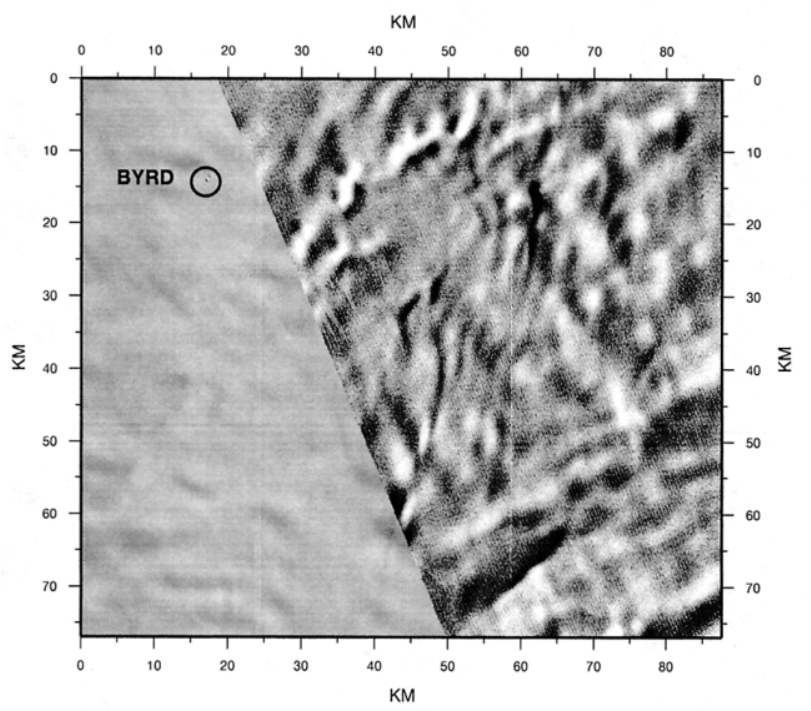

ection of basal water, if present (Anandakrishnan and Alley, 1997a). These gradients are determined predominantly by the surface-elevation gradient and are only slightly modified (by a factor roughly equal to $10 \%$ ) by the bed-elevation gradient. In some places the basal slope is large and would steer basal water away from the direction of ice flow. The effect of the bed channel is to capture water and concentrate it along the central axis. This is also where the fastest flow occurs. Overall, however, the $50 \mathrm{~km}$ spacing of the bed-elevation data is coarse, leaving the significance of these hydropotentials suspect on the $5 \mathrm{~km}$ scale elsewhere in the region. Analysis of this effect will be more appropriate when the $5 \mathrm{~km}$ spaced grid of ice thicknesses is made available (personal communication from D. D. Blankenship, 1996).

\section{BSSN}

The downstream end of the BSSN was resurveyed as part of this recent work. As reported in Chen and others (1998), and mentioned earlier, the difference in velocity at Byrd station is not considered significant. An additional reason for this interpretation is that the present surface strain rates measured over the downstream part of the BSSN were nearly identical with those measured in the initial survey 30 years ago (Whillans, 1979).

\section{Relict flow stripes}

One observation that does not indicate equilibrium conditions is the orientation of a set of flow stripes located at the grid's southeast corner (Fig. 7). These were not easily detected in our imagery, but using lower-spatial-resolution images at a different sun illumination angle, Hodge and Doppelhammer (1996) observed and interpreted them as a likely onset area of Ice Stream D. The different visual appearance of the two images is the result of a stronger contrast enhancement applied to the Hodge and Doppelhammer image to compensate for its lower resolution. Our velocity measurements discount the possibility that this area is an onset and indicate the present flow direction runs obliquely to these flow stripes. Because flow stripes can only form parallel to flow, there must have been some change in the flow field. At the present flow rate of $30 \mathrm{ma}^{-1}$, it would have taken approximately 1000 years for these $30 \mathrm{~km}$ long stripes to form.

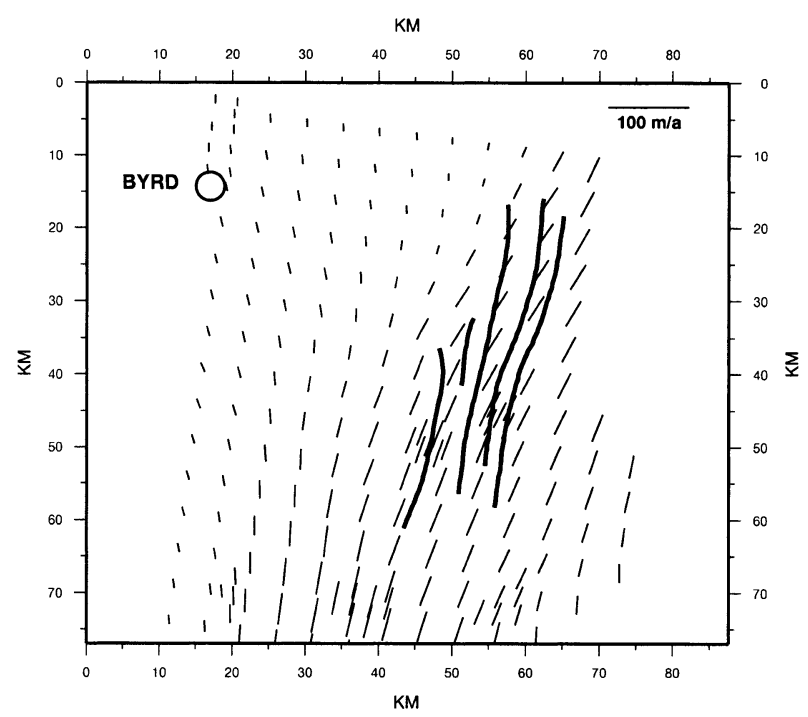

Fig. 7. Composite of Landsat imagery in upstream area of survey grid and tracing of flow stripes from imagery superimposed on measured velocities. (Additional Landsat imagery provided by S. Hodge.) 
These flow stripes are slightly curved, and the deviation angle between their long axis and current flow direction lessens downstream. Since the present flow speed is nearly uniform in this region, the inference is that the downstream ends of the flow stripes have been under the influence of the recent flow field longer than the upstream ends. Also, the upstream ends occur where shear strain rates are unusually large (Fig. 4), providing further evidence that this ice is experiencing a changed flow pattern. We conjecture that the flow stripes were generated when Ice Stream $\mathrm{C}$ was more active, but either the recent stagnation of Ice Stream C or an inland migration of Ice Stream D caused this change in the flow pattern.

\section{GONGLUSIONS}

The procedure used to identify the onset of streaming flow was successfully applied to Ice Stream D. Precise GPS-survey data were used to determine surface velocity. When these were combined with published datasets of surface and bed elevation, regions exhibiting laminar flow were distinguished from those obeying streaming flow. The onset occurs downstream from the center of an overdeepening in the channel occupied by the incipient ice stream, as well as downstream from a kink in the velocity profile. It is unlikely that velocity data, satellite imagery or bed- or surface-elevation maps alone would provide sufficient information to locate this, or any other, onset area.

The direction taken by the accelerating ice follows the dominant bed channel, and basal sliding occurs over much of the surveyed grid. There is no strong indication of large rates of thickness change within the grid, and the strain-rate field upstream of Byrd station is stable over the past 30 years. However, there are flow stripes in the upstream corner of the grid misaligned with present flow direction, indicating a different flow direction once existed in that region, lasting as long as 1000 years.

\section{ACKNOWLEDGEMENTS}

We thank J. MacNamee, C. Briscoe, K. Johnson and C. Jackson who assisted in the field survey. GPS receivers were provided by W. Krabill. D. MacAyeal assisted in software use. J. Bamber and M. Stenoien provided elevation datasets. S. Hodge provided the digital image of the relict flow stripes. R. Alley provided an excellent review which improved the text. This research was supported by U.S. National Science Foundation grant OPP-9317627.

\section{REFERENCES}

Alley, R. B. 1990. Multiple steady states in ice--water-till systems. Ann. Glaciol., 14, 1-5.

Anandakrishnan, S. and R. B. Alley. 1997a. Stagnation of Ice Stream C, West Antarctica by water piracy. Geophys. Res. Lett., 24(3), 265-268.

Anandakrishnan, S. and R. B. Alley. 1997b. Tidal forcing of basal seismicity of Ice Stream C, West Antarctica, observed far inland. 7. Geophys. Res., 102(B7), 15,183-15,196.

Bamber, J. L. 1994. A digital elevation model of the Antarctic ice sheet derived from ERS-1 altimeter data and comparison with terrestrial measurements. Ann. Glaciol., 20, 48-54.

Bamber, J. L. and R. A. Bindschadler. 1997. An improved elevation dataset for climate and ice-sheet modelling: validation with satellite imagery. Ann. Glaciol., 25, 439-444.
Bell, R. E., D. D. Blankenship, C. A. Finn, D. L. Morse and T. A. Scambos. 1996. Evidence for geologic control on ice sheet behaviour: the onset of streaming in West Antarctica. [Abstract.] EOS, 77 (46), Fall Meeting Supplement, F140.

Bentley, C. R. 1987. Antarctic ice streams: a review. F. Geophys. Res., 92(B9), 8843-8858.

Bentley, C. R. and M. B. Giovinetto. 1991. Mass balance of Antarctica and sea level change. In Weller, G., C. L. Wilson and B. A. B. Severin, eds. International Conference on the Role of the Polar Regions in Global Change: proceedings of a conference held Fune 11-15, 1990 at the University of Alaska Fairbanks. Vol. II. Fairbanks, AK, University of Alaska. Geophysical Institute/Center for Global Change and Arctic System Research, 481-488.

Bindschadler, R. 1997. Actively surging West Antarctic ice streams and their response characteristics. Ann. Glaciol., 24, 409-414.

Bindschadler, R. A. and P. L. Vornberger. 1990. AVHRR imagery reveals Antarctic ice dynamics. EOS, 71 (23), 741-742.

Bindschadler, R., P. Vornberger, D. Blankenship, T. Scambos and R. Jacobel. 1996. Surface velocity and mass balance of Ice Streams D and E, West Antarctica. 7. Glaciol., 42(142), 461-475.

Budd, W. 1969. The dynamics of ice masses. ANARE Sci. Rep., Ser. A (IV). Glaciology 108.

Chen, X., R. A. Bindschadler and P. L. Vornberger. 1996. Preliminary determination of ice flow velocity in West Antarctica using high precision GPS measurements. In ION GPS-96, 17-20 September 1996, Kansas City, Missouri. Proceedings. Washington, DC, Institute of Navigation, 1853-1861.

Chen, X., R. A. Bindschadler and P. L. Vornberger. 1998. Determination of velocity field and strain-rate field in West Antarctica using high precision GPS measurements. Surv. Land Inf. Syst., 58(4), 247-255.

Doake, C. S. M. and E.W. Wolff. 1985. Matters arising. Flow law for ice in polar ice sheets. Nature, 318(6041), 83.

Drewry, D. J., ed.. 1983. Antarctica: glaciological and geophysical folio. Cambridge, University of Cambridge. Scott Polar Research Institute.

Engelhardt, H. and B. Kamb. 1997. Basal hydraulic system of aWest Antarctic ice stream: constraints from borehole observations. 7. Glaciol., 43(144), 207-230.

Gudmundsson, G. H., C. F. Raymond and R. Bindschadler. 1998. The origin and longevity of flow stripes on Antarctic ice streams. Ann. Glaciol., 27, $145-152$.

Hodge, S. M. and S. K. Doppelhammer. 1996. Satellite imagery of the onset of streaming flow of Ice Streams C and D, West Antarctica. 7. Geophys. Res., 101(C3), 6669-6677.

Hughes, T. 1977. West Antarctic ice streams. Rev. Geophys. Space Phys., 15(1), 1-46.

Jacobson, H. P. and C. F. Raymond. 1998. Thermal effects on the location of ice stream margins. F. Geophys. Res., 103(B6), 12,111-12,122.

Kamb, B. 1991. Rheological nonlinearity and flow instability in the deforming bed mechanism of ice stream motion. 7. Geophys. Res., 96(B10), $16,585-16,595$.

MacAyeal, D. R., R. A. Bindschadler, S. Shabtaie, S. Stephenson and C. R. Bentley. 1987. Force, mass, and energy budgets of the Crary Ice Rise complex, Antarctica. 7. Glaciol., 33(114), 218-230. [Correction in f. Glaciol., 35(119), 1989, 151-152.]

McIntyre, N. F. 1985. The dynamics of ice-sheet outlets. F. Glaciol., 31(108), 99-107.

Paterson, W. S. B. 1980. Ice sheets and ice shelves. In Colbeck, S. C., ed. Dynamics of snow and ice masses. New York, Academic Press, 1-78.

Paterson, W. S. B. 1994. The physics of glaciers. Third edition. Oxford, etc., Elsevier.

Raymond, C. 1996. Shear margins in glaciers and ice sheets. F. Glaciol., 42(140), 90-102.

Rose, K. E. 1979. Characteristics of ice flow in Marie Byrd Land, Antarctica. 7. Glaciol., 24(90), 63-75.

Scambos, T. A. and R. A. Bindschadler. 1991. Feature maps of Ice Streams C, D and E, West Antarctica. Antarct. F. U.S., 26(5), 312-314.

Stephenson, S. N. and R. A. Bindschadler. 1990. Is ice-stream evolution revealed by satellite imagery? Ann. Glaciol., 14, 273-277.

Whillans, I. M. 1979. Ice flow along the Byrd Station strain network, Antarctica. F. Glaciol., 24(90), 15-28.

Whillans, I. M. 1983. Glaciological parameters, their measurement and significance. Ice movement. In Robin, G. de Q., ed. The climatic record in polar ice sheets. Cambridge, etc., Cambridge University Press, 70-77.

Whillans, I.M. 1987. Force budget of ice sheets. In Van der Veen, C. J. and J. Oerlemans, eds. Dynamics of the West Antarctic ice sheet. Dordrecht, etc., D. Reidel Publishing Co., 17-36.

Whillans, I. M. and C. J. van der Veen. 1993. New and improved determinations of velocity of Ice Streams B and C, West Antarctica. 7. Glaciol., 39(133), 483-490.

Whillans, I. M. and C. J. van der Veen. 1997. The role of lateral drag in the dynamics of Ice Stream B, Antarctica. 7. Glaciol., 43(144), 231-237. 